\title{
ELEMENTOS PARA UMA RECONSTRUÇÃO DA HISTÓRIA UNIVERSAL: PENSAMENTO E MEMÓRIA NA FILOSOFIA NEGATIVA DE HEGEL
}

Thiago Mendes Borges*

\begin{abstract}
Resumo: $\mathrm{O}$ artigo trata do conceito hegeliano de "história universal" e expõe a possibilidade da prosa hegeliana como uma tríplice matriz de inteligibilidade para o desenvolvimento de uma prosa crítica da história como uma explicitação da finitude dos impérios.
\end{abstract}

Hegel - Filosofia da História - História Universal - Prosa Crítica

Para o leitor do texto hegeliano, um dos temas de saída é a própria entrada na trama que envolve as ideias deste autor. As negações, as oposições e as contradições: tecido fino e essencial, constituinte da realidade efetiva. Não haveria progresso do espírito sem esta trama, para Hegel e para nós. O "fim da história", em sua apropriação confusa e insidiosa no século $\mathrm{XX}$, também compõe as ruínas deste reencontro no crepúsculo. Tudo se passa como a revelação do espírito absoluto também reconciliasse as críticas que o pensamento hegeliano sofrera ao longo de suas interpretações neste sentido histórico. Se a ave de minerva só bate asas no entardecer, nada mais útil à própria história que pensar o "fim da história", visto que já ocorreu do oriente para o ocidente, o dia da história. A compreensão da história pressupõe a Hegel, a visão do berço, da gênese dos acontecimentos que deflagraram a história. A compreensão vasta de todas as transformações e destruições. Tudo aquilo que a "ciência nova" descartaria nos processos teóricos e cartesianos, entrariam para o "cálculo" hegeliano: tudo aquilo que é, será negado. Interessa para Hegel, tanto o que era sólido, como o que se desmanchara no ar, tanto o lixo e como a versão da derrota e dos perdedores. A transformação

\footnotetext{
* UNIFESP, thiagomborges@gmail.com, artigo redigido a partir da dissertação apresentada à Universidade Federal de São Paulo como requisito parcial para a obtenção do título de mestre em filosofia sob orientação do Prof. Dr. Silvio Rosa Filho.

${ }^{1}$ Bernard Bourgeois resume a tese de Fukuyama em dois momentos: "1) a história, em sua atualidade mais objetiva, que anula em particular seu desvio comunista, impõe a constatação de que a democracia liberal representa 'o ponto final da evolução ideológica da humanidade', 'a forma final de todo governo humano', e portanto, 'o fim da história'; mas 2) esta constatação não é senão a verificação positiva da afirmação especulativa hegeliana do fim da historia, que, em troca, explica e justifica o conteúdo de tal constatação pela análise do processo de reconhecimento (originário na luta do mestre e do escravo), o desejo humano de reconhecimento, grande motor da história, satisfazendo-se plenamente no fim desta." (BOURGEOIS, 2004:161)
} 
disso para aquilo, tudo que vem a ser, tudo. A história e seu fim. Nada para nada ${ }^{2}$. Nada demais para o "espírito de contradição organizado" 3 como se atirar no inferno para anos de tradição filosófica, o chamado "devir". A incessante batalha para isolar variáveis e teorizar em nome de uma estabilidade que não parece "dormir no tempo": o esforço cartesiano posto em causa. Este constante perecimento-esvanecimento-apodrecimento, esta mobilidade que emerge em cisões, mas não "compreende" a realidade cindida como pede a tradição cientifica de objetos e fragmentos. Não haveria expediente para a filosofia hegeliana que não contemplasse um sentido racional do presente, cada instante desconectado do todo, ou individualidades preteridas pela totalidade. O pensamento de Hegel nos exige uma racionalidade que contemple silogismo tal que consiga desmobilizar (e agrega-la ao conjunto) a razão instrumental - para ficar num signo mais reconhecido a nossa recente tradição crítica reconhecer os elementos opostos da realidade. O que leva essa dissertação a uma série de questões: Que terror foi aquele da Revolução Francesa que não parte da história?" "Pisar em flores inocentes", não seria esse um fardo necessário rumo à completude das séries dessa consciência rumo a seu encontro com o Espírito do Mundo? Não seria próprio desse Espírito do Mundo e sua transitoriedade (seu trânsito pelo tempo) se edificar entre "mortos e feridos" ${ }^{5}$ ? O que dizer então do contemporâneo, se a grande tarefa do filosofo é pensar o presente? O que está encarnado nesse tempo que merece reconhecimento? Para "dar conta do recado",

\footnotetext{
${ }^{2}$ Nas palavras de Hegel: "De início, a natureza originariamente determinada da individualidade, sua essência imediata, não está ainda posta como agente, e assim chama-se faculdade especial, talento, caráter etc. Essa coloração característica do espírito deve ser considerada como o único conteúdo do próprio fim, e, com absoluta exclusividade, como a realidade. Quem se representasse a consciência como ultrapassando esse conteúdo, e querendo levar à efetividade um outro conteúdo, representar-se-ia a consciência como um nada labutado rumo ao nada.”(FE, §401)

${ }^{3}$ ARANTES, P.E., 1996:213

4 “' 'Já foi dito que a Revolução Francesa resultou da filosofia, e não é sem razão que a filosofia tem sido chamada de Weltweisheit [sabedoria do mundo]; pois não só é verdade em si e para si como a pura essência das coisas, mas também verdade em sua forma viva conforme mostrada nas coisas do mundo. Não deveríamos, portanto, contradizer afirmação de que a revolução teve seu primeiro impulso da filosofia. [...] Desde que o Sol surgiu no firmamento e os planetas revolvem ao redor dele, nunca se percebeu que a existência do homem centra-se na cabeça, isto é, no pensamento, e inspirado nele o homem constrói o mundo da realidade [...] só agora o homem avançou a ponto de reconhecer o princípio de que o pensamento deve governar a realidade espiritual. Por conseguinte, essa foi uma gloriosa alvorada mental. Todo pensamento sendo compartilhado no júbilo dessa época. As emoções de um caráter elevado estremeceram a mente dos homens naquela época; um entusiasmo spiritual espalhou-se pelo mundo, como se a reconciliação entre o divino e o secular fosse agora realizada' Isso, é claro, não impediu que Hegel analisasse friamente a necessidade interna dessa explosão da liberdade abstrata, transformando-se em seu oposto, o Terror revolucionário autodestrutivo."(ZIZEK, 2013:133)

${ }^{5} \mathrm{E}$ ao pensar-se em transitoriedade, podemos pensar naquelas personalidades históricas do mundo? Aqueles grandes homens cada vez mais invisíveis nos tempos modernos: "Uma personalidade histórica do mundo não é tão desprovida de imaginação que não possa adaptar sua ambição às circunstâncias, mas também não é muito ponderada. Está dedicada a um objetivo, aconteça o que acontecer. Por isso homens assim poderão chegar a tratar outros interesses grandes, ou até sagrados, sem muita reflexão - comportamento esse que realmente os sujeita à repreensão moral. Uma personalidade tão poderosa tem de pisar em muita flor inocente, esmagando muitas coisas em seu caminho." (HEGEL, 2001:82)
} 
para "dar notícia" daquele raio em céu claro, qual é o "caminho" rumo à descontinuidade do pensamento tradicional? Em tempo de indivíduos, após um século de barbárie, de guerra constante e extinção, qual é o brilho de uma história universal? Podemos contar com aquele projeto universal cosmopolita e garantir a insociável sociabilidade ${ }^{6}$ entre imigrantes, estrangeiros e xenófobos? Quais polícias e políticas serão mobilizadas para aquele outro, ou melhor, com nós enquanto outros em terras estranhas? No presente imediato, qual projeto de universidade compreenderia as lições hegelianas sobre o estágio dos "povos sem história" sem extrair cirurgicamente fragmentos delas para destratar o sistema filosófico na sua totalidade? Contemplemos nesse mesmo cair da noite a presença daqueles seres humanos primitivos ${ }^{7}$ e daqueles já iluminados do "entendimento": estes que poderiam se valer de ombros do gigante Hegel para endossar ações excludentes - para ficarmos na história, "novos terrorismos": agindo sob novas formas de terror ${ }^{8}$, estaríamos dispostos a nos deixar levar a mais "sofrimento e dor" rumo ao inicio? Cessemos as questões da consciência de si. Elas irrompem o texto rumo à realidade que experimenta um pouco de "...uma ética.", sem que nenhuma força seja reprimida. Daí um quinhão da poderosa liberdade imanente do texto hegeliano, não se dissocia do ser, não se separa e compõe a vocação da integralidade. Um pensamento que Pensa a crítica ${ }^{9}$, erra também, serve e assenhoreia ao mesmo tempo os

\footnotetext{
${ }^{6}$ A Quarta Proposição de Kant em "Idéia de uma história universal de um ponto de vista cosmopolita": "O meio de que a natureza se serve para obter o desenvolvimento de todas as suas disposições é o antagonismo destas na sociedade, na medida em que ele se torna, finalmente, causa de uma ordem legal das mesmas disposições. Entendo aqui por antagonismo a sociabilidade insociável dos homens, isto é, a sua tendência para entrar em sociedade; essa tendência, porém, está unida a uma resistência universal que, incessantemente, ameaça dissolver a sociedade. Esta disposição reside manifestamente na natureza humana. O homem tem uma inclinação para entrar em sociedade, porque em semelhante estado se sente mais como homem, isto é, sente o desenvolvimento das suas disposições aturais. Mas tem também uma grande propensão para se isolar, porque depara ao mesmo tempo em si com a propriedade insocial de querer dispor de tudo a seu gosto e, por conseguinte, espera resistência de todos os lados, tal como sabe por si mesmo que, da sua parte, sente inclinação para exercer a resistência contra os outros."

7 "O ser humano é esta noite, este nada vazio, que contém tudo na sua simplicidade - uma riqueza infindável de muitas representações, imagens, das quais nenhuma lhe pertence ou não estão presentes. Esta noite, o interior da natureza, que existe aqui - o puro si - em representações fantasmagóricas, é noite em toda parte, na qual nasce aqui uma cabeça ensanguentada - e ali outra aparição branca e terrível, de repente aqui diante dela, e depois desaparece simplesmente. Avistamos esta noite quando olhamos os seres humanos nos olhos - uma noite que se torna terrível." (HEGEL, "Jeanaer Realphilosophie" in Früe politische System, 1974: 204 apud ZIZEK, 2013:201)

8 "Desse tumulto seria o espírito relançado ao seu ponto de partida, ao mundo ético e ao mundo real da cultura, que se teria apenas refrescado e rejuvenescido pelo temor do senhor, que penetrou de novo nas almas. O espírito deveria percorrer de novo esse ciclo da necessidade, e repeti-lo sem cessar, se o resultado fosse somente a compenetração efetiva da consciência-de-si e da substância. [Seria] uma compenetração em que a consciência de si, que experimentou contra ela a força negativa de sua essência universal, não quereria saber-se nem encontrarse como este particular, mas só como universal; portanto também poderia arcar com a efetividade objetiva do espírito universal, a qual a exclui enquanto particular.” (FE, §594)

${ }^{9}$ Michel Foucault sobre Hegel em "A Ordem do Discurso": "Penso, no entanto, que minha dívida, em grande parte, é para com Jean Hyppolite. Bem sei que sua obra se coloca, aos olhos de muitos, sob o reinado de Hegel e que toda a nossa época, seja pela lógica ou pela epistemologia, seja por Marx ou por Nietzsche, procura escapar de Hegel: e o que procurei dizer há pouco a propósito do discurso é bem fiel ao logos hegeliano. Mas escapar
} 
desígnios daquele Espírito do Mundo: nenhum episódio histórico está desatrelado do fim ${ }^{10}$ absoluto. Voltemos ao pouco que sabemos sobre as circunstâncias que cercavam o filósofo alemão e suas lições. Um cenário macabro ${ }^{11}$, por suposto! O silêncio do mundo atravessava as aulas noturnas do professor Hegel que contava a seus discípulos sobre o esvanecimento de cada uma das figuras da consciência rumo ao Espírito Absoluto em meio a velas e castiçais. A “certeza sensível” acredita-se, acha que sabe de si e das coisas tombadas no imediato ao seu toque. Quando para um instante e se dá conta que cada coisa possui outros adjetivos, deixa a pele e dilacera-se em "percepção". Agora que aquele um possui vários outros, a "percepção" entra em colapso: começa a duvidar. E duvida até transformar para outra figura, o “entendimento". Trajada de discernimento, a consciência pondera sobre as coisas, analisa, desfragmenta, reconstrói e isso a leva também a um possível entrave ao próximo estágio: ao repetir essas decomposições rumo ao infinito, ela se perde em meio aos fragmentos de suas análises e não sabe mais recompô-los. A consciência perde a noção do todo. Da compreensão que não se pode apreender a toda a realidade, surge uma nova pele: agora ela é consciência de si e se permite conhecer. Neste trajeto rumo a si mesmo, a "consciência de si" atenta-se que é necessário "um outro" para que possa se afirmar enquanto ser. Desta constatação, surge um embate mortífero dentro dela mesmo, numa dialética digna de senhor e escravo. Para superar essa cisão, a consciência precisa deixar de crer na possibilidade de servidão generalizada do mundo (estoicismo), que não há nada a ser feito (ceticismo) e que deve resignar-se e sofrer passivamente na condição de escravo (consciência infeliz). Para tanto, há dois caminhos a serem necessariamente cruzados. O primeiro: a consciência deve perder o medo da morte. Precisa viver o negativo, viver os erros, permitir o nada, saber-se enquanto dilaceração constante. O segundo: a consciência deve trabalhar e saber da importância deste esforço rumo

realmente de Hegel supõe apreciar exatamente o quanto custa separar-se dele; supõe saber até onde Hegel, insidiosamente, talvez, aproximou-se de nós; supõe saber, naquilo que nos permite pensar contra Hegel, o que ainda é hegeliano; e medir em que nosso recurso contra ele é ainda, talvez, um ardil que ele nos opõe, ao termo do qual nos espera, imóvel e em outro lugar." (FOUCAULT, M. L'Ordre du discours, Leçon inaugurale ao Collège de France prononcée le 2 décembre 1970, Éditions Gallimard, Paris, 1971 in FOUCAULT, M. A ordem do discurso. São Paulo: Loyola, 1999:72)

10 “A morte do homem divino, como morte, é a negatividade abstrata, o resultado imediato do movimento,que só se consuma na universalidade natural. A morte perde essa signifi-cação natural na consciência-de-si espiritual, ou seja, torna-se seu conceito indicado acima: a morte daquilo que imediatamente signi-fica, - do não-ser deste Singular, - se transfigura na universalidade do espírito, que vive em sua comunidade, e nela cada dia morre e ressuscita."

${ }^{11}$ Sobre a estadia de Hegel em Nuremberg: "Em 14-12-1810, escreveu a Karl Ludwig von Knebel, um ex-oficial prussiano, tradutor de Propércio e Lucrécio, dando conta de algumas de suas preocupações com tumultos que afetavam os costumes na cidade pequena. Falou num autêntico "museu dos horrores": 'Recentemente, um certo senhor von Haller estourou os miolos. A mulher do senador von Strömer jogou no rio o bebê de sua filha e agora está encarcerada. Nos próximos dias, um homem que manteve relações incestuosas com a filha será morto no suplício da roda; e a moça será decapitada, porque ambos mataram o bebê que tiveram. Outras meninas estão grávidas. Há dias, a filha de um casal conhecido meu, com 14 anos de idade, fugiu com um ator; pouco depois, outra jovem lhe seguiu o exemplo." (KONDER, 1991:29, grifo nosso.) 
à universalidade. "Suprassumidos" estes dois caminhos, a consciência sabe das impossibilidades das passividades imobilistas das figuras anteriores (que foram necessárias e transportaram a própria até ali) e está formada para demorar na próxima casa, a "razão". Neste momento, a consciência sabe que participa de um todo muito maior que das percepções anteriores. Ela se insere na humanidade e seus atos não estão desconectados deste movimento maior. Entretanto, esta inserção é deveras hostil. O palco é repleto de forças contrárias a suas atuações: sua singularidade está a todo tempo ao ponto de desaparecer em meio às leis deste teatro. $\mathrm{O}$ perigo deste estágio também reside na possibilidade da consciência se limitar as tais leis e vive-las, reproduzi-las e não criticá-las. Se a consciência ousa investigar as origens históricas destas leis, nega-las radicalmente e consequentemente, superá-las...A consciência ousa sua nova estação, o "espírito". Agora, enquanto espírito rememora constantemente suas formas predecessoras, medita sobre todas suas peles e as inclui no seu caminhar: superando, preservando e destinando a ser outra coisa. Para continuar, o espírito se vale de uma energia essencial para seu movimento: a paixão ${ }^{12}$. Impulsionado por esta paixão, o espírito se prepara para se superar rumo "saber absoluto". A última figura reconcilia os extremos, ela estava presente no começo da jornada da consciência e faz do conceito, sua ferramenta. Depois de narrar a odisseia da consciência, sobraria os fantasmas aos discípulos de Hegel. E o que viria depois? Descansaria no sétimo dia, o saber absoluto? Qual a lógica viria após tamanha destruição, mortes e fantasmagorias? Depois da terra arrasada, qual é a história que encerra as memórias e os pensamentos de Hegel? Cessam-se as possíveis questões daquele fado ${ }^{13}$ das aulas sobre a Fenomenologia e aporta-se no tempo presente, esse continente, tomando o "hegelianês" como "idioma nativo". Consideremos então, a reflexão sobre a história, enquanto uma meditação sobre as ruínas, e, a possibilidade de que a prosa hegeliana nos forneça uma matriz de inteligibilidade para uma reconstrução peculiar ao mundo do espírito: mesmo que, para a regressão vinculada à noção de uma "proto-história", haveria de se

\footnotetext{
${ }^{12} \mathrm{O}$ interesse da particular da paixão é, portanto, inseparável da participação do universal, pois é também da atividade do particular e de sua negação que resulta o universal. É o particular que se desgasta em conflitos, sendo em parte destruído. Não é a idéia geral que se expõe ao perigo na oposição e na luta. Ela se mantém intocável e ilesa na retaguarda. A isso se deve chamar astúcia da razão: deixar que as paixões atuem por si mesmas, manifestando-se na realidade, experimentando perdas e sofrendo danos, pois é esse o fenômeno no qual uma parte é nula e a outra afirmativa. O particular geralmente é infinito perante o universal, os indivíduos são sacrificados e abandonados. A idéia recompensa o tributo da existência e da transitoriedade, não por ela própria, mas pelas paixões dos indivíduos. (HEGEL, 1995:35)

${ }^{13}$ Como cantou Amália Rodrigues em "Tudo Isto É Fado": Perguntaste-me outro dia/Se eu sabia o que era o fado/Disse-te que não sabia/Tu ficaste admirado/Sem saber o que dizia/Eu menti naquela hora/Disse-te que não sabia/Mas vou-te dizer agora/Almas vencidas/Noites perdidas/Sombras bizarras/Na Mouraria/Canta um rufia/Choram guitarras/Amor ciúme/Cinzas e lume/Dor e pecado/Tudo isto existe/Tudo isto é triste/Tudo isto é fado/Se queres ser o meu senhor/E teres-me sempre a teu lado/Não me fales só de amor/Fala-me também do fado/E o fado é o meu castigo/Só nasceu pra me perder/O fado é tudo o que digo/Mais o que eu não sei dizer.
} 
estabelecer uma fronteira entre mundo do espírito e história natural, de um lado, e, de outro, para o desencadeamento de um processo que torna imprescindível, desde o início, a apresentação de um "fim da história". Dado a dinâmica da modernidade (crises e cisões) torna-se possível o desenvolvimento de uma prosa crítica da história, na medida em que a explicitação da finitude dos impérios, (compreendida como uma história da soberania), signifique uma redução do processo da história a um desenrolar uniforme e problemático. Por fim, sem conclusões ou sugestões, reforça-se a questão: na medida em que a efetividade do "fim da história" implica uma descontinuidade singular, seria pertinente passar uma vez mais a palavra à filosofia negativa de Hegel, de modo a permitir-lhe interrogar, criticamente, é claro, o limiar para além do qual o processo cumulativo das continuidades solicita o recurso à ideia subjacente de uma pós-história? A essa "máquina de moer impérios"14 que é a filosofia da história, bem longe de subscrever as facilidades de um "imaginário mobilista", o andamento da prosa hegeliana explicita a refutação de um império por outro ou de uma soberania por outra? Por esta via, "a verdadeira teodicéia" seria menos uma procissão de teologemas do que uma metafísica retificada: esta última, seria para resumir, a anamorfose legível daquela. Se para Gerard Lebrun, a história mundial é um texto, isto não significa de modo algum um reducionismo a mais, já que, na prosa hegeliana da história comparece uma convicção tão subjacente como inegável ${ }^{15}$. Com Herbert Marcuse, tais épocas de crise e de colisão dispõem de um episódio histórico mundial sem precedentes. Para uma estimativa da pertinência do episódio histórico ao conceito filosófico, em 1959, no epílogo que redigiu para Razão e Revolução, Marcuse encerra que a ideia de uma forma díspar da razão e liberdade, "sonhada tanto pelo idealismo dialético como pelo materialismo, ainda parece uma utopia. Mas o triunfo das formas retrógradas e conservadoras não desmerecem a verdade desta utopia." ${ }^{16}$ Tal embricamento entre a dinâmica das crises e os modelos críticos leva Marcuse a insistir no teor conflitivo da prosa hegeliana: "o sistema pudesse ser chamado com propriedade uma "filosofia negativa", tal como o foi, naquela época por seus adversários ${ }^{17}$. Se assim o pensamento hegeliano da história aparece como uma arma contra as filosofias positivas, poderíamos sugerir uma retrospecção hegeliana da revolução francesa em tempos de contrarrevolução. Por texto, sem dúvida; porém, começa a se tornar menos enigmática uma expressão que o caracteriza como prosa crítica da história. Com Paulo Eduardo Arantes, os

\footnotetext{
${ }^{14}$ Assim falava Gerard Lebrun em $O$ Avesso da Dialética.

${ }^{15}$ [convicção de] que a história propriamente dita se deixa vislumbrar nas épocas de crise e de 'colisões', quando a referência às normas éticas e morais se torna vã e os objetos finitos dos homens se vêem submergidos por uma situação nova. É somente então que surgem as possibilidades propriamente históricas. (LEBRUN, 1988:21)

${ }^{16}$ MARCUSE, 2004:374

${ }^{17}$ MARCUSE, 2004:9
} 
caminhos se bifurcam. Por um lado, a "prosa da história" assinala, para os povos imersos no sono da não-história, no torpor a-histórico, no "estado de inconsciência de si" , o ingresso desses povos no limiar da história universal. Envolvimento que promete um desenvolvimento, ruptura com a vida apenas imediata, o espírito se reconcilia, pois, com a caducidade. Compreendamos esse imperativo: é preciso ligar a negatividade do tempo à negatividade do Conceito; "o poder do tempo que se desenha de início como perda e ruína deve ser subordinado ao poder do Conceito, onde a perda é metamorfoseada em ganho, onde o que desaparece dá testemunho de sua pertinência à história" ${ }^{18}$.Por outro lado, o acompanhamento filosófico do processo revolucionário francês permite situar a atitude de Hegel diante do acontecimento-chave dos tempos modernos. Tudo se passa, neste caso, como se fosse necessário captar do interior do edifício da história a sua manifestação do conjunto, enxergar o sol a partir dos vitrais da catedral. Assim, se for correto falar em "realismo hegeliano", será possível discernir entre o pressuposto real dessa grande relato de formação, ascensão e supremacia do Terceiro Estado (senha, para Arantes, da própria filosofia da história) e os sucessivos confiscos de uma vitória que teve profundidade revolucionária e alcance popular. Concluamos, por hora, desta maneira: a reflexão sobre a história universal começa com uma meditação sobre as ruínas, se o texto da história só emerge no momento em que o “entendimento prosaico" ocupa o lugar da primitiva representação poética ${ }^{19}$, coloca-se então o problema da irradiação da subjetividade, questão que concerne ao sol interior da consciência. Ora, o espírito - só e junto a si mesmo como unidade da subjetividade e da objetividade - põese como qualidade da própria inteligência na objetividade. Ainda parece ser um dos pontos até agora totalmente descuidados, e de fato um dos mais difíceis, na Doutrina do Espírito, na sistematização da inteligência, apreender a situação e significação da memória, e conceber sua conexão orgânica com o pensar. A memória como tal é, ela mesma, o modo apenas exterior, o momento unilateral da existência do pensar; "a passagem é, para nós ou em si, a identidade da razão e do modo da existência; essa identidade fez que a razão exista então em um sujeito como atividade sua: assim a memória é o pensar." ${ }^{20}$ Essa conexão orgânica entre memória e pensamento, ao propor uma resolução para o problema da cisão entre individualidade e espírito mundial do tempo evoca a proposta adorniana presente em nossa introdução ${ }^{21}$. Perguntemo-nos: quanto maior a uniformidade processual do conjunto maior

\footnotetext{
${ }^{18}$ ARANTES, 2000: 211

${ }^{19}$ ARANTES, 2000:194

${ }^{20}$ HEGEL, 1995:258

21 “O próprio Hegel tinha concebido a história universal uniforme meramente por força de suas contradições. [...] Todavia, a descontinuidade e a história universal precisam ser pensadas juntas. Riscar essa história universal
} 
seria a potência inaudita das contradições? Esta questão, suscitada por um dos modelos críticos da dialética negativa ${ }^{22}$, têm o mérito de afastar todo um conjunto de releituras que ora reduzem ora extrapolam o escopo da prosa hegeliana da história ${ }^{23}$. Em outros termos, Adorno nos coloca na via de uma reconstrução da história universal tal como Hegel a concebeu em toda a sua amplitude: longe de precipitar-se rumo a uma conciliação terminal e forçada, o texto adorniano cultiva um tipo singular de paciência sem cair na apologia do status quo. Tudo se passa como se a positividade própria ao hegelianismo berlinense fosse mais negativa do que a negatividade daqueles intelectuais que foram chamados contemporâneos do neohegelianismo de esquerda ${ }^{24}$. Tudo se passa, inversamente, como se a negatividade própria ao desencantamento berlinense testemunhasse uma positividade mais profunda do que aquela expressa pelos que postularam o neoliberalismo como sinônimo do fim da história e como defesa de uma "grande ruptura" ${ }^{25}$. Suspende-se, provisoriamente, este idioma esquisito de falar sobre aquilo que é.

\section{BIBLIOGRAFIA}

ADORNO, T. W., Dialética Negativa, Rio de Janeiro: Editora Zahar, 2009.

ARANTES, P. E., Hegel a ordem do tempo; São Paulo: Polis, 2000. , Idéias ao Léu In Novos estudos, São Paulo, n. 25: CEBRAP, 1989. , Ressentimento da Dialética: dialética e experiência intelectual em

Hegel: antigos estudos sobre o ABC da miséria alemã, São Paulo: Paz e Terra, 1996.

BOURGEOIS, B. Hegel: os atos do espírito. São Leopoldo: UNISINOS, 2004.

FOUCAULT, M. A ordem do discurso. São Paulo: Loyola, 1999

HABERMAS, J., Discurso filosófico da modernidade; São Paulo: Martins Fontes, 2000 .

HEGEL, G.W.F, Enciclopédia das Ciências Filosóficas em Compêndio (1830). I. A Ciência da Lógica, II. São Paulo: Loyola, 1995. ,Fenomenologia do Espírito, Petrópolis: Vozes, 2007. Filosofia da História, Brasília: UNB, 2008.

, Lecciones sobre la filosofía de La historia universal; Madrid: Alianza

Editorial, 1982.

como resíduo de uma crença metafísica confirmaria intelectualmente a mera facticidade enquanto a única coisa a ser conhecida e por isso aceita, do mesmo modo que a soberania, que subordinava os fatos à marcha triunfal do espírito uno, a ratificara antes como expressão dessa história.”(ADORNO, 2009:266)

${ }^{22}$ Referimo-nos ao subtítulo reservado por Adorno para a terceira parte da Dialética Negativa: "Espírito do mundo e história natural" . (ADORNO, 2009:250-298)

${ }^{23}$ C.f. HABERMAS, 2000

${ }^{24}$ Cf. ROSA FILHO, 2009: 76.

${ }^{25}$ Este é, como se sabe, o título de um livro de Francis Fukuyama. 
KONDER, Leandro. Hegel: a razão quase enlouquecida. Rio de Janeiro, Campus, 1991.

LEBRUN, G., O Avesso da dialética - Hegel à luz de Nietzsche, São Paulo: Cia. Das Letras, 1988.

MARCUSE, H., Razão e Revolução: Hegel e o advento da teoria social, Rio de Janeiro: Paz e Terra, 2004.

ROSA FILHO, S., Eclipse da moral: Kant, Hegel e o nascimento do cinismo contemporâneo, São Paulo: Barcarolla, Discurso Editorial, 2009.

ŽIŽEK, S., Menos que nada, São Paulo: Boitempo, 2013. 